\title{
Reliability analysis of household rainwater harvesting tanks in the coastal areas of Bangladesh using daily water balance model
}

\author{
$\underline{\text { Md. Rezaul Karim }}{ }^{\text {a }}$, Rifath Ara Rimi ${ }^{\text {b }}$ and Md. Solaiman Billah ${ }^{\text {a }}$ \\ ${ }^{a}$ Department of Civil and Environmental Engineering, Islamic University of Technology (IUT), Board Bazar, \\ Gazipur-1704, Bangladesh \\ Email: rezaulmd@gmail.com; renegade0072006@yahoo.com \\ ${ }^{b}$ Department of Civil Engineering, Ahsanullah University of Science \& Technology (AUST), Tejgaon \\ Industrial Area, Dhaka-1208, Bangladesh.
}

\begin{abstract}
Rooftop rainwater harvesting has received an increased attention as a potential alternative water supply source both in the coastal and arsenic affected areas of Bangladesh. Over the last several years, projects have been undertaken to promote and install both household and community based rainwater harvesting systems in order to mitigate drinking water problem both in the coastal and arsenic affected areas in the country. The annual average rainfall is the coastal area of Bangladesh is more than $2400 \mathrm{~mm}$ and rainwater harvesting has been practiced for a long time for drinking water supply. For household rainwater harvesting, the capacity of the storage tanks are 1000 to 5000 liters, provided under several projects of government and donor agencies. The optimum storage volume required by a household has not been investigated considering family size and demand, roof types and rainfall. As a result, most of the households can avail water from rainwater tanks for about 6 months and rest of the year, they have to depend on other unreliable and distance sources like pond or pond sand filter (PSF) water.
\end{abstract}

With the aim of assessing the currently used household rainwater harvesting system in the coastal areas of Bangladesh, design curves for the storage volume were developed for three climate conditions (i.e. dry, average and wet years) considering available roof catchment area (10 to $\left.50 \mathrm{~m}^{2}\right)$, generated runoff and household demand ( 2 to $12 \mathrm{lpcd}$ ) for a typical family of 6 members using mass curve. From the historical daily rainfall data over 10-years period from 1998 to 2007, three separate climate conditions were selected based on annual rainfall. Years corresponding to minimum and maximum annual rainfall were considered as dry and wet year, respectively. The average year was considered the year having annual rainfall closed to the average annual rainfall over 10 years' period. Moreover, spreadsheet based daily water balance model was developed considering daily rainfall, contributing roof area and generated runoff from the roof catchment area, storage (tank) volume, water uses and overflow from the tank to assess the reliability of the currently used water tanks (1000 to 5000 liters).

The analysis showed that the currently used rainwater tanks in the coastal areas of Bangladesh are insufficient to meet the yearly drinking and cooking water demand. Under wet and dry climate conditions; the maximum achievable reliability is about $70 \%$. The maximum reliability that can be achieved under average climate condition varies from 70 to $90 \%$ and the reliability does not increase significantly beyond $3000 \mathrm{~L}$ tank volume. A large quantity of water is lost as spilled water even with a tank size of $5000 \mathrm{~L}$. This water can be used for other purposes if larger tanks are used to capture the excessive spilled water. This analysis also showed that although a huge amount of water is lost as spilled water, a significant amount of water would need to be collected from other sources like pond or PSF water during non-availability of water into the storage tanks. This water volume depends on tank size and reliability, an increase in tank size decreases the water volume collected from other sources. With increase of reliability, the water required to be collected from other sources also decreases.

Keywords: $\quad$ Water balance model, reliability, rainwater harvesting, coastal area of Bangladesh 


\section{INTRODUCTION}

Rooftop rainwater harvesting is receiving increased attention worldwide as an alternative source of domestic water in water scarce regions (Meera and Ahammed, 2006). This is acknowledged as a sustainable source of water that has less impact on the environment and nowadays, rainwater is used as a source for numerous domestic applications like drinking, cooking, bathing, laundry, toilet flushing, hot water supply and for gardening purposes (Pathak and Heijnen, 2006). Roof-collected tank rainwater is the major source of untreated drinking and domestic water supply in Australia, New Zealand and other countries (Simmons et al. 2001; Heyworth et al. 2006). In the recent years, rooftop rainwater harvesting has received an increased attention as a potential alternative water supply source both in the coastal and arsenic affected rural areas in Bangladesh. During the last few years, several projects have been undertaken to promote and install both household and community based rainwater harvesting systems in order to mitigate drinking water problem both in the coastal and arsenic affected areas in the country (Ahmed et al. 2005; Karim, 2010).

Bangladesh as a tropical country, receives high seasonal rainfall all over the country. The seasonal high rainfall and suitable roof catchments in the rural areas make rainwater harvesting (RWH) a potential alternative water supply option in the country (Ahmed, 2002). The average annual rainfall is about $2400 \mathrm{~mm}$ and in most part of the country, people normally can have the access to rainwater for 6 to 8 months on an average. In the coastal areas, scarcity of potable water is very acute (Kamruzzaman and Ahmed, 2006; Islam et al. 2011) as suitable aquifers at shallow depths are rarely available and surface water especially the river water is highly saline and turbid. Rain-feed ponds water, pond sand filters (PSF) and direct collection of rainwater are the major sources of drinking water in most parts of the coastal zones. About $28 \%$ of the country's total population lives in these areas (Islam et al. 2011) and supply of safe water is one of the important environmental issues for human health and sustainable development in the coastal areas. Rainfall in the coastal areas is much higher and roof catchments are suitable (Karim, 2010); thus rainwater harvesting has a good potential to supply drinking and cooking water in the coastal areas of Bangladesh.

For a reliable rainwater harvesting systems, the storage volume must be assessed carefully in order to meet the year-long demand of a family. For household rainwater harvesting in the coastal areas of Bangladesh, the volume of the rainwater tanks varies from 1000 to 5000 liters or more (Karim, 2010), which are promoted under some specific projects of government and donor agencies without proper analysis of the storage volume required by a household considering family size and demand, roof types and rainfall. As a result, most of the households can avail water from rainwater tanks for about 6 months and rest of the year, they have to depend on other unreliable and distance sources like PSF or pond water. An in-depth understanding of the effectiveness of any proposed onsite rainwater harvesting is necessary for a reliable rainwater harvesting scheme.

The optimum storage volume of rainwater tanks has been investigated by numerous researchers (Liaw and Tsai, 2004; Khastagir and Jayasuriya, 2010; Imteaz et al. 2011a). Various methodologies such as continuous mass balance simulations, non-parametric approaches based on probability matrix methods, and statistical methods are used. The most common methodology is the behavioral analysis that uses continuous simulation to assess inflow, outflow and change in storage volume of the rainwater tanks according to a mass balance equation (Fewkes and Butler, 2000; Liaw and Tsai, 2004; Imteaz et al. 2011b; Imteaz et al. 2012).

The main objective of this present study is to assess the currently used household rainwater harvesting system in the coastal areas of Bangladesh. For the purpose, design curves for the storage volume of rainwater tanks were developed for three climate conditions (i.e. dry, average and wet years) considering available roof catchment area, generated runoff from the roof catchment area and household water demand (drinking and cooking) using mass curve. Moreover, a spreadsheet based daily water balance model was developed to assess the reliability of the currently used water tanks in the coastal areas of Bangladesh. Reliability is defined as percentages of days in a year when rainwater tank is able to meet the water demand of family of 6 members.

\section{METHODOLOGY}

Mass curve techniques based on daily water demand (drinking and cooking) and rainwater supply was used to develop the design curves for storage volume calculation. A behavioral model according to Imteaz et al. (2011b) was developed in Microsoft Excel considering daily rainfall, contributing roof area and generated runoff, storage (tank) volume, water uses and overflow from the tank. The model was run at a daily time resolution with daily rainfall amount for three different years (dry, average and wet years). The daily runoff volume was calculated by multiplying the rainfall amount with the contributing roof area and runoff coefficient. For this study, runoff coefficient for the roof catchment was considered as 0.90 . The generated 
runoff was assumed to divert to the connected storage tank. Available storage capacity was compared with the accumulated daily runoff. If the accumulated runoff was bigger than the storage tank volume, excess water (spilled water) was deducted from the accumulated runoff. Amount of water use(s) is deducted from the daily accumulated/stored runoff amount, if sufficient amount of water is available in the storage. In a situation, when sufficient amount of water is not available in the storage, model will assume that the remaining water demand is supplied from other sources like PSF or rain-feed pond.

The model calculates daily rainwater use, daily water storage in the tank, daily spilled water volume and daily water needed from other sources like PSF or pond. In addition, model calculates accumulated annual rainwater use, accumulated annual spilled water and accumulated annual water needed from other sources. The water balance equation for the study is given by:

$$
\begin{aligned}
& S_{t}=V_{t}+S_{t-1}-D \\
& S_{t}=0, \text { for } S_{t}<0 \\
& S_{t}=C, \text { for } S_{t}>C
\end{aligned}
$$

where, $S_{t}$ is the cumulative water stored in the rainwater tank $(L)$ after the end of $t^{\text {th }}$ day; $V_{t}$ is the harvested rainwater (L) on the $\mathrm{t}^{\text {th }}$ day; $\mathrm{S}_{\mathrm{t}-1}$ is the storage in the tank $(\mathrm{L})$ at the beginning of $\mathrm{t}^{\text {th }}$ day; $\mathrm{D}$ is the daily rainwater demand $(\mathrm{L})$, and $\mathrm{C}$ is the capacity of rainwater tank $(\mathrm{L})$. On a particular day if the water storage was greater than the tank capacity $\mathrm{C}$, the excess water will spill over and the tank storage level at the end of the day is reset equal to $C$. The amount of water spilled and the water supplied from other sources are given by

$$
\begin{aligned}
& \text { Spilled water }=S_{t}-C \text { for } S_{t}>C \\
& \text { Water needed from other sources }=D-S_{t} \text { for } S_{t}<D
\end{aligned}
$$

In this calculation, time based reliability is used to quantify the performance of rainwater harvesting system, which can be defined by the following equation:

$$
R_{e}=\frac{N-U}{N} x 100
$$

where, Re is the reliability of the tank to be able to supply intended demand (\%); $U$ is the number of days in a year the tank was unable to meet the demand, and $\mathrm{N}$ is the total number of days in a year.

\subsection{Data}

Daily rainfall data for 10-years period from 1998 to 2007 was collected from Bangladesh Meteorological Department for a coastal meteorological station located at Satkhira. From the historical daily rainfall data (1998-2007), three separate climate conditions were selected based on total annual rainfall. Years corresponding to minimum and maximum annual rainfall were considered as dry and wet year, respectively. The average annual rainfall over 10 years' period was $1855 \mathrm{~mm}$, which is very closed to annual rainfall in $2007(1872 \mathrm{~mm})$, so the year 2007 was considered as representative average year. Selected years and corresponding annual rainfall amounts are shown in Table 1. For the three climate conditions, design curves for storage volumes were developed using mass curve considering roof sizes from 10 to $50 \mathrm{~m}^{2}$ and drinking and cooking water demand from 2 to $12 \mathrm{lpcd}$, which are the typical range of drinking and cooking water requirement for rural communities in Bangladesh (Ahmed and Rahman, 2000). An average household of 6 members is assumed, thus daily water requirement of 12 to $72 \mathrm{~L} /$ day were considered in this calculation. Several reliability curves were also developed for a wide range of domestic rainwater tanks sizes (1000 to 5000 liters), roof area (10 to $40 \mathrm{~m}^{2}$ ), and drinking and cooking water demand for the household. Spilled water volume and water collected from other sources (when the harvested rainwater is not available) to meet the demand were also calculated using the model.

\section{RESULTS AND DISCUSSION}

Table 1. Annual rainfall for dry, average and wet years.

\subsection{Storage Volume-Demand Relationship}

Design curves were developed for the average, wet and dry year conditions to estimate the storage volume required for a household of 6 members. A typical storage volume-demand relationship for an average year 
condition is shown in Figure 1. As shown in Figure 1, the storage volume increases when demand increases and storage volume decreases when catchment areas increases. A family of 6 members with a water demand of $72 \mathrm{~L} /$ day for drinking and cooking would need to have a storage volume of more than $21.2 \mathrm{~m}^{3}$ of water for an average year rainfall condition with a roof catchment area of $10 \mathrm{~m}^{2}$. Table 2 shows the optimum storage volume required for year-long water supply for an average household with a daily water demand of $60 \mathrm{~L} /$ day under three climatic conditions (dry, average and wet years). The required storage volume for average and wet climate conditions is not significantly difference (Table 2). It is interesting to observe that the storage volume required under dry climate condition is smaller than that based on average and wet year climate conditions. Analysis of the rainfall data showed that the number of rainy days in 1999 was comparatively higher than other two years; the rainfall was more effective in meeting the daily demands of the households with a relatively smaller storage tank.

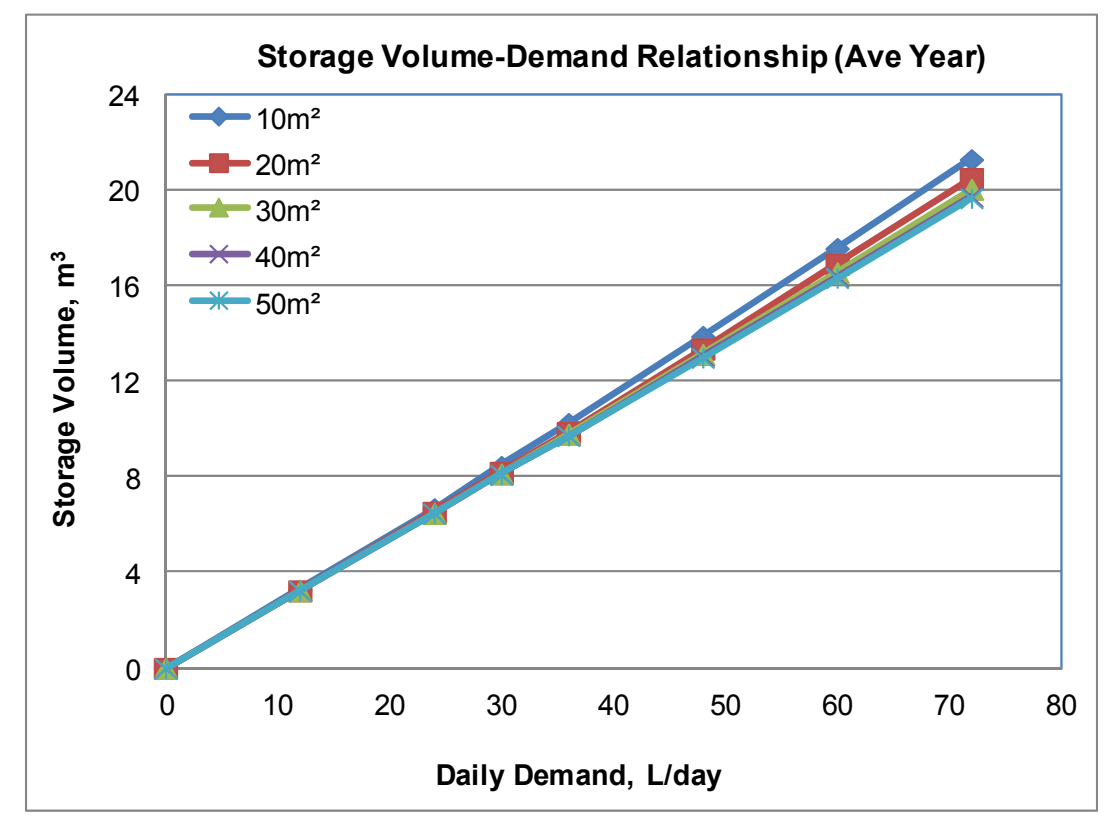

Figure 1. Typical storage volume-demand relationship of rainwater tank in the coastal areas of Bangladesh under average rainfall condition.

The available storage tanks for household rainwater harvesting in the coastal areas of Bangladesh vary from 1000 to $5000 \mathrm{~L}$ (Karim, 2010). This analysis showed that the storage volume of the currently used rainwater tanks is much lower than that required for year-long uses of harvested rainwater. During the non-supply period, rural people normally collect water from unreliable and distance sources like pond water or PSF. The pond water is found to be seriously microbial contaminated (Islam et al. 2011) and in most cases, people were found to use some in-house treatments like alum coagulation or filtration to treat the pond water before drinking. Several studies (Ahmed et al. 2005; Islam et al. 2011) showed that performance of PSF is still unsatisfactory to produce safe water. Rural people especially women who are responsible to collect drinking water would need to travel a long distance (some cases more than $2 \mathrm{~km}$ ) and also to have a long queue to collect PSF water. The design curves can be used in calculating the required storage volume of rainwater tanks for yearlong water supply. Such curves can also be developed for other uses of rainwater for reliable and sustainable rainwater harvesting in the coastal or other water scarce areas.

Table 2. Storage volume required for different catchment areas.

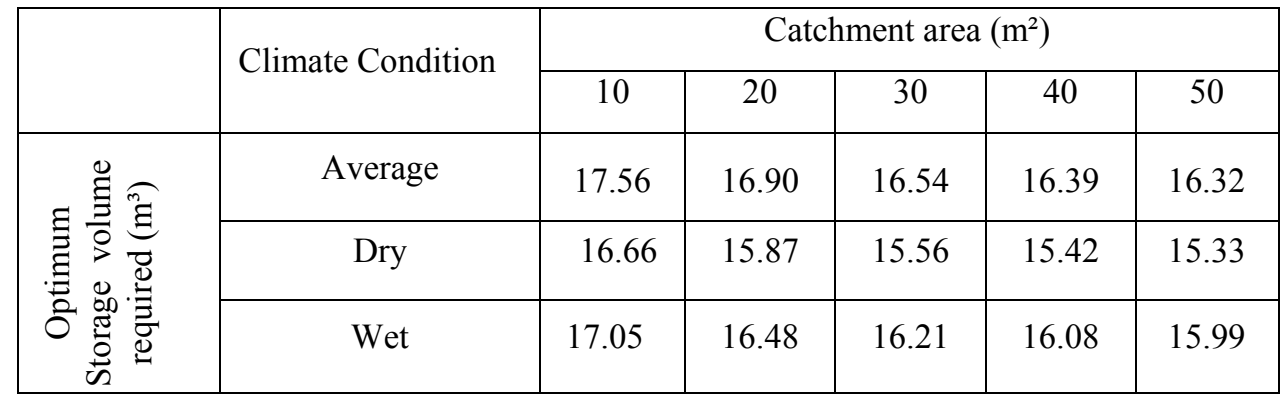




\subsection{Reliability}

Figure 2 shows the reliability curves under different climatic conditions (wet, average and dry years) for different tank sizes and roof catchment areas of 10 to $40 \mathrm{~m}^{2}$ for an average household with 10 lpcd of water consumption. The maximum reliability that can be achieved under average climate condition varies from 70 to $90 \%$ and the reliability does not increase significantly beyond the tank volume of $3000 \mathrm{~L}$. In general, the reliability increases with tank sizes; however $100 \%$ reliability cannot be achieved even with larger catchment area and tank capacity of $5000 \mathrm{~L}$. Under wet and dry climate conditions; the achievable reliability does not significantly varies with increase of catchment area and tank size and the maximum achievable reliability is about $70 \%$. This means that a tank size of more than $4000 \mathrm{~L}$ can meet the drinking and cooking water demand for maximum $70 \%$ of the days in a year.

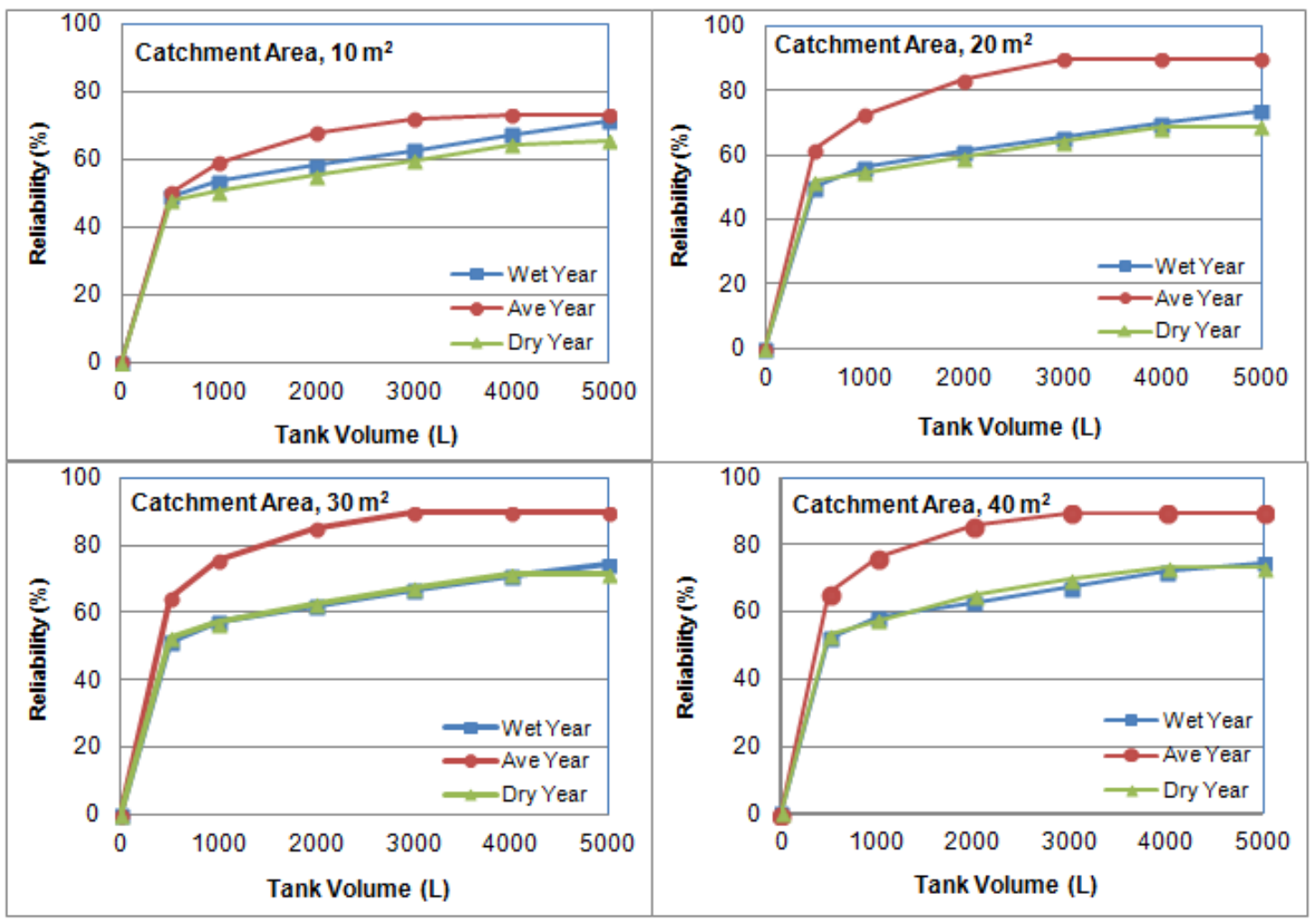

Figure 2. Reliability curves for a household with a water demand of $10 \mathrm{lpcd}$ for different roof catchments.

Figure 3 shows the spilled water (annual) curves varying with tank sizes under different climate conditions (dry, average and wet climate). It is found that volume of spilled water can be reduced with an increase in tank size. It is also found that even with a smaller catchment area $\left(10 \mathrm{~m}^{2}\right)$; the spilled volume is more than the maximum tank capacity of $5000 \mathrm{~L}$. The spilled water volume under wet climate is higher than that calculated under average or dry weather condition. Figure 3 also indicates that spilled water volume significantly increases with increase in catchment area. For a $40 \mathrm{~m}^{2}$ roof catchment area, ratio of spilled water to tank volume for $5000 \mathrm{~L}$ tank varies from 9 to 13. This huge spilled water can be used for other domestic purposes like washing and bathing and thus the potential uses of rainwater can be increased with a larger tank size.

As shown in Table 3, a significant amount of water has to be collected from other sources like pond or PSF during nonavailability of water in the storage tanks, although a significant amount of rainwater is spilled from the tank. This water volume depends on tank size and reliability, an increase in tank size decreases the required

Table 3. Volume of water collected from other sources (ratio)

\begin{tabular}{|c|c|c|c|}
\hline \multirow{2}{*}{$\begin{array}{l}\text { Tank } \\
\text { size }(\mathrm{L})\end{array}$} & \multicolumn{3}{|c|}{ Required water volume from other sources } \\
\cline { 2 - 4 } & Dry year & Ave Year & Wet year \\
\hline 500 & 20.52 & 14.93 & 20.74 \\
\hline 1000 & 9.30 & 5.12 & 9.08 \\
\hline 2000 & 3.81 & 1.54 & 4.06 \\
\hline 3000 & 2.22 & 0.75 & 2.37 \\
\hline 4000 & 1.47 & 0.56 & 1.52 \\
\hline 5000 & 1.18 & 0.45 & 1.11 \\
\hline
\end{tabular}


water collected from other sources. If reliability increases, the water required to be collected from other sources also decreases.

Overall, the water supply efficiency of RWH implementation under various roof areas and climatic conditions vary widely (Mehrabadi et al. 2013). Jenkins (2007) also demonstrated that the climate condition of the study area imposes a major impact on the effectiveness of rainwater tank systems. It is expected that various combinations of climate condition, roof area, tank volume, and water demand can lead to widely different reliabilities. It is necessary to document and quantify the expected water storage under various climate conditions and water demands to adopt cost-effective tank volume. The temporal variability of rainfall has an important impact on the storage volume and thus planning rainwater harvesting systems. In an area with more or less uniform monthly rainfall would require less storage tank than the area with high seasonal variation of rainfall and thus the rainfall distribution patterns need to be carefully evaluated. In calculating the required storage volume, Imteaz at el. (2012) demonstrated that daily water balance model give a realistic tank volume, whereas calculation based on monthly average rainfall data overestimates the tank size.

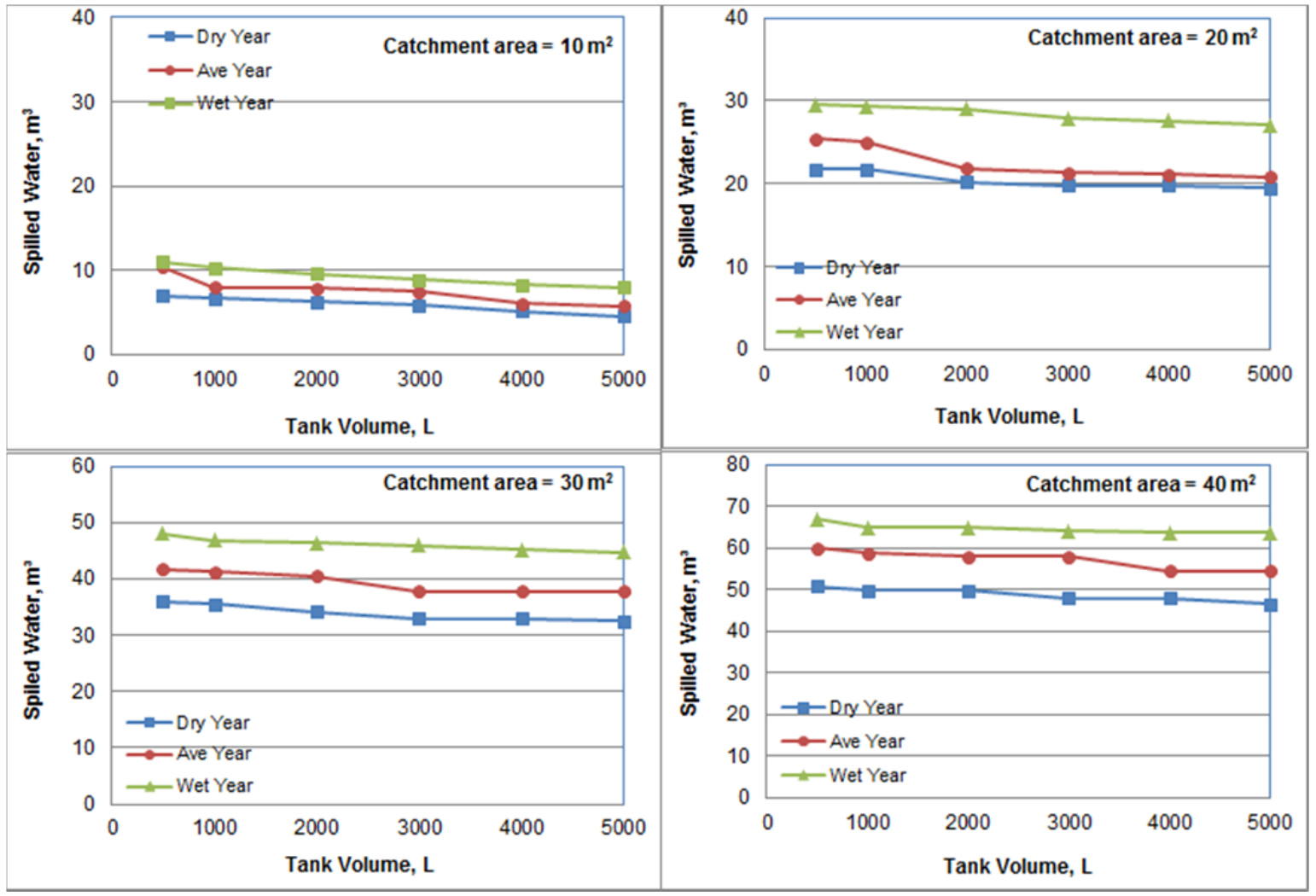

Figure 3. Spilled water for different roof catchments under different climatic conditions.

\section{CONCLUSIONS}

In this paper, reliability of household based rainwater tanks in the coastal area of Bangladesh was investigated under different climatic conditions (dry, average and dry condition), roof area, tank volume, household drinking and cooking water demand and spilled water from the tank. The analysis used the recorded daily rainfall data instead of monthly average rainfall data. The design curves for optimum storage volume required for a household of 6 members under different climatic conditions were developed, which can be used as a tool to estimate the required tank volume for yearlong drinking and cooking water supply from rainwater harvesting system. The analysis reveals that the currently used storage tanks in the coastal areas of Bangladesh are insufficient to meet the yearlong drinking and cooking water demand. The analysis based on average daily rainfall gives comparative smaller storage tank volumes than that based on wet or dry climate conditions.

The present analysis indicates that $100 \%$ reliability cannot be achieved with the tank sizes currently used for household rainwater harvesting in the coastal areas of Bangladesh. The maximum reliability that can be achieved under average climate condition varies from 70 to $90 \%$ and the reliability does not increase significantly beyond the tank volume of 3000 L. Under wet and dry climate conditions, the maximum 
achievable reliability is about $70 \%$. This analysis also indicates that significant amount of water is lost as spilled water for tank sizes varies from 1000 to $5000 \mathrm{~L}$. The spilled water volume significantly increases with increase in catchment area. The potential uses of rainwater can be increased by capturing the huge spilled water with a larger tank. The analysis also reveals that a significant volume of water would need to be collected from other sources during non-availability of harvested rainwater into the tanks.

Tank capacity is an important consideration to maximize rainwater storage. In order to determine the optimum tank volume, amount of rainfall and its distribution, roof area and water uses are the critical factors. There are numerous optimum solutions with different combinations of storage volumes, roof sizes and rainwater demand. For a reliable and sustainable rainwater harvesting, this type of analysis should be conducted for a particular geographical area of Bangladesh before undertaking a rainwater harvesting project for domestic water supply.

\section{REFERENCES}

Ahmed, M. F. (2002). Alternative Water Supply Options for Arsenic Affected Areas of Bangladesh. ITNBangladesh and WSP-South Asia, Dhaka, Bangladesh.

Ahmed, M. F., Shamsuddin, S. A. J., Mahmud, S. G., Rashid, H., Deere, D. and Howard, G. (2005). Risk Assessment of Arsenic Mitigation Options (RAAMO). APSU, Dhaka, Bangladesh.

Ahmed, M. F. and Rahman, M. M. (2000). Water supply and sanitation rural and low income urban communities. ITN-BUET, Dhaka, Bangladesh.

Fewkes, A. and Butler, D. (2000). Simulating the performance of rainwater collection systems using behavioral models, Build. Serv. Eng. Res. Technology. 21(2), 99-106.

Heyworth, J. S., Glonek, G., Maynard, E. J., Baghurst, P. A. and Finlay, J. J. (2006). Consumption of untreated tank rainwater and gastroenteritis among young children in South Australia. International Journal of Epidemiology. 35, 1051-1058.

Imteaz, M. A., Adeboye, O.B., Rayburg, S. and Shanableh A. (2012). Rainwater harvesting potential for southwest Nigeria using daily water balance model, Resources, Conservation and Recycling. 62, 51-55.

Imteaz, M. A., Ahsan, A., Naser, J. and Rahman, A. (2011a). Reliability analysis of rainwater tanks in Melbourne using daily water balance model, Resources, Conservation and Recycling. 56, 80-86.

Imteaz, M.A., Rauf, A. and Aziz, A. (2011b). eTank: A decision support tool for optimizing rainwater tank size, International Congress on modeling and Simulation MODSIM 2011. December, Perth, Australia.

Islam, M.A, Sakakibara, H., Karim, M. R., Sakine, M. and Mahmud, Z. H. (2011). Bacterial assessment of alternative water supply options in Coastal Areas of Bangladesh, Journal of Water and Health. 9.2, 415428.

Jenkins, G.A. (2007). Use of continuous simulation for the selection of an appropriate urban rainwater tank, Australian Journal of Water Resources. 11(2), 231-246.

Kamruzzaman, A. K. M. and Ahmed, F. (2006). Study of performance of existing pond sand filters in different parts of Bangladesh. In 32nd WEDC International Conference. 377-380.

Karim, M.R. (2010). Assessment of rainwater harvesting for drinking water supply in Bangladesh, Journal of Water Science and Technology: Water Supply. 10.2, 243-249.

Khastagir, A. and Jayasuriya, N. (2010). Optimum sizing of rainwater tanks for domestic water conservation, Journal of Hydrology. 381, 181-188.

Liaw, C.H. and Tsai, Y.L. (2004). Optimum storage volume of rooftop rain water harvesting systems for domestic use, Journal of American Water Resources Association. 40(4), 901-912.

Meera, V. and Ahammed, M. M. (2006). Water quality of rooftop rainwater harvesting systems: a review. Journal of Water Supply: Research and Technology, AQUA. 55, 257-268.

Mehrabadi, M. H. R., Saghafian, B. and Fashi, F. H. (2013). Assessment of residential rainwater efficiency for meeting non-potable water demands in three climate conditions, Resources, Conservation and Recycling. 73, 86-93.

Pathak, N. and Heijnen, H. (2006). Health and hygiene aspects of rainwater for drinking. In 32nd WEDC International Conference. 393-396.

Simmons, G., Hope, V., Lewis, G., Whitmore, J. and Gao, W. (2001). Contamination of potable roofcollected rainwater in Auckland, New Zealand. Water Research. 35(6), 1518-1524. 